\title{
From Philosophy of Science to Philosophy of Literature (and Back) via Philosophy of Mind: Philip Kitcher's Philosophical Pendulum*
}

\author{
Bence NANAY
}

Received: 24.09 .2012

Final version: 25.02 .2013

BIBLID [0495-4548 (2013) 28: 77; pp. 257-264]

ABSTRACT: A recent focus of Philip Kitcher's research has been, somewhat surprisingly in the light of his earlier work, the philosophical analyses of literary works and operas. Some may see a discontinuity in Kitcher's oeuvre in this respect - it may be difficult to see how his earlier contributions to philosophy of science relate to this much less mainstream approach to philosophy. The aim of this paper is to show that there is no such discontinuity: Kitcher's contributions to the philosophy of science and his more recent endeavors into the philosophy of literature and of music are grounded in the same big picture attitude towards the human mind - an attitude that he would undoubtedly call 'pragmatic': one that emphasizes the importance of those mental processes that are not (or not entirely) rational.

Keywords: Philip Kitcher; Philosophy of Literature; Philosophy of Science; Emotions.

RESUMEN: El análisis filosófico de obras literarias y óperas se ha convertido en un objeto de estudio reciente para Philip Kitcher, algo quizá sorprendente a la vista de su trabajo anterior. Hay quien puede percibir una discontinuidad en la obra de Kitcher a este respecto: puede ser difícil apreciar cómo sus anteriores contribuciones a la filosofía de la ciencia se relacionan con este otro tipo menos mayoritario de filosofía. El propósito de este artículo es mostrar que no hay tal discontinuidad: las contribuciones de Kitcher a la filosofía de la ciencia y sus empresas más recientes en filosofía de la literatura y de la música se basan en la misma visión general del espíritu humano, una actitud que indudablemente él denominaría pragmática: enfatiza la importancia de los procesos mentales que no son (o no completamente) racionales.

Palabras clave: Philip Kitcher; filosofía de la literatura; filosofía de la ciencia; emociones.

\section{Introduction}

A recent focus of Philip Kitcher's research has been, somewhat surprisingly in the light of his earlier work, the philosophical analyses of literary works and operas (Kitcher 2007, 2008, 2009, 2013, 2014; Kitcher and Schacht 2004, 2006). As he says:

I take the supposed barrier between literature and philosophy to be highly permeable. That barrier has been breached again and again in the recent cultural history of the west. (Kitcher 2013, 18)

Some may see a discontinuity in Kitcher's oeuvre in this respect-it may be difficult to see how his earlier contributions to philosophy of science relate to this much less mainstream approach to philosophy.

The aim of this paper is to show that there is no such discontinuity: Kitcher's contributions to the philosophy of science and his more recent endeavors into the philosophy of literature and of music are grounded in the same big picture attitude towards the human mind - an attitude that he would undoubtedly call 'pragmatic': one that emphasizes the importance of those mental processes that are not (or not entirely) rational.

* This work was supported by the EU FP7 CIG grant PCIG09-GA-2011-293818 and the FWO Odysseus grant G.0020.12N. I am grateful for Philip Kitcher's comments. 


\section{Three grades of philosophical involvement}

Kitcher argues that fictional works can do real philosophizing and, as a result, philosophers can't ignore them. He distinguishes between three grades of philosophical involvement of fictional works (an homage to Quine's 'three grades of modal involvement').

The first grade is when a fictional work uses a philosophical argument or text to enrich the fiction (Kitcher 2013, 16). The example Kitcher gives is Dickens, who names Mr. Gradgrind's children in Hard Times 'Adam Smith' and 'Malthus'. There is nothing particularly philosophical in these literary or other fictional texts: they merely make reference to philosophy without themselves aiming to have any philosophical contribution at all. The fictional works are about philosophy, but not even about substantive philosophical ideas.

The second grade of philosophical involvement goes further (Kitcher 2013, 17). The example Kitcher gives is Dante's Inferno where Hell is organized according to Aristotelian principles. Note that in this second grade of philosophical involvement, the fictional works are still about philosophy, but now about substantive philosophical ideas that may color one's experience of the fictional work itself.

The third grade of philosophical involvement goes even further: the fictional works explore genuinely philosophical questions (Kitcher 2013, 17-21). As Kitcher says:

Although the issues may descend from philosophical texts (and the writer may adopt the formulations of them that occur in those texts), the author develops answers of his/her own, instead of accepting the proposals of others. (Kitcher 2013, 17)

It is this third grade of philosophical involvement that Kitcher is interested in and all his writings on the philosophy of literature and of music could be taken to be explorations of the possibilities in which fictional works (of his liking: Joyce, Wagner, Mann, Shakespeare, Proust, Mahler, Britten) could be interpreted as making genuine contributions to philosophy.

\section{But is it philosophy at all?}

Here is a problem with this general approach, one that Kitcher is very much aware of: for someone (like Kitcher himself) who is trained as an analytic philosopher, literary or other fictional works do not come even close to satisfying the minimal requirements of being genuine philosophical writings.

First of all, they do not present arguments: unambiguously formulated premises that would necessitate an unambiguously formulated conclusion. As Kitcher is ready to admit:

Wagner and Joyce do not argue. They do not even present precisely-articulated theses about the worth and value of human lives. Nevertheless, they do philosophy, real philosophy that can lead listeners and readers to improved perspectives on a (if not the) central philosophical question. The philosophy lies in the showing. Instead of a rigorously-connected sequence of clear and precise declarative sentences, we are offered a rich delineation of possibilities-accompanied by a tacit injunction: Consider this. (Kitcher 2013,26) 
Further, fictional works influence us emotionally: they seduce us to feel or think in some way or another, sometimes even in spite of our rational beliefs. Philosophy, in contrast, does not use such suspicious means of convincing: it proceeds only in rational and emotion-free logical steps. If a philosophical argument appeals to emotions, it is, as it is widely held, at least in the Anglo-american tradition, a bad argument. But then how could we take fictional works to be genuine contributions to philosophy?

Kitcher's answers to these charges are not always as convincing as one would hope. In response to the first charge, he points out that there are some philosophers, even very good philosophers and even contemporary, highly regarded analytic philosophers-an example he mentions is Nancy Cartwright-whose work is important not because of the arguments they present, but because of the way they "describe, exactly and in rich detail, some scientific work of a type overlooked by orthodox philosophical accounts; by considering the phenomena she portrays, her readers are expected to recognize the superiority of the precise claims about the sciences she offers as replacements for orthodoxy" (Kitcher 2013, 267).

One potential worry is about how widespread this strategy is. As we have seen, Kitcher explicitly mentions Nancy Cartwright's work as an example, and there may be others (Kendall Walton's Mimesis as Make-Believe (Walton 1990) is one that comes to mind), but this still leaves open the question about whether we can take this to be a genuine trend in philosophy rather than some isolated examples of somewhat idiosyncratic philosophers.

But even if we grant this point, the general problem with Kitcher's proposal (and one he is very much aware of, see Kitcher 2013, 16-20) is the following. Even if we accept that both philosophy and literature offer 'a rich delineation of possibilitiesaccompanied by a tacit injunction: Consider this' (Kitcher 2013, 26), this would still be compatible with the view according to which philosophy, but not literature, offers the rich delineation of possibilities in a dispassionate, purely rational, manner. Thus, we would still have a radical discontinuity between philosophy and literature.

This takes us to the second charge: the one about the different use of emotions in literature and philosophy: while literature manipulates our emotions, philosophy is the dispassionate quest for truth. Here is Kitcher's way of dealing with this problem:

I propose a broader view of the activity of philosophizing, one in which what goes on in the mind of the subject can involve a range of different psychological processes-including experiments in imagination and emotional reactions to them-and in which the texts and sounds that generate philosophical changes of mind can be far more various than the luminous rows of precise declarative sentences. (Kitcher 2013, 20)

The main worry about this response is that it is unlikely to move hard-core analytic philosophers. What they consider to be philosophizing has little to do with emotions and imagination. Some serious case would need to be made about the "psychology of philosophy' in order to change this stance. And Kitcher only gestures towards ways of fleshing out what he considers to be the 'psychology of philosophy'. I argue that we can use some recent empirical results in order to fill in the details of the picture Kitcher is painting. 


\section{The psychology of philosophy}

There has been a lot of research recently on what has been labeled as the 'philosophy of philosophy': the philosophical discussion of what philosophy is: for example, is it an a priori or an a posteriori enterprise (see Williamson 2007)? Kitcher is interested in a somewhat different set of problems that could be labeled as the "psychology of philosophy': what psychological processes are (or can be) involved when we are philosophizing. And he questions some deeply rooted mainstream assumptions about the psychology of philosophy.

In the philosophy of philosophy literature, it is taken for granted that philosophizing, whether or not it is entirely a priori, is the dispassionate quest for truth. This is the assumption that Kitcher questions. But he has written very little about this question specifically. The aim of this section and the next is to expand on Kitcher's insights in support of his conclusions and general methodology and to point out that his claims are supported by some recent empirical studies (see also Nanay 2013b).

He analyzes the mainstream assumptions about the psychology of philosophy as the conjunct of two sets of claims. The first one is this:

The psychological movement that occurs in someone who is thinking through a philosophical issue can be exhaustively characterized in terms of changes in belief (or knowledge): the philosophizing subject passes through a sequence of cognitive states, and, if the philosophizing is well done, the relations among the contents of these states conform to canons of good evidencethat is, if the person comes to believe some new proposition on the basis of prior apprehension of other propositions, then the former (the new conclusion) must stand in appropriate logical relations (broadly construed) to the latter (the previously-adopted premises). (Kitcher 2013, 19)

In other words, the only mental states involved in the psychology of philosophy are purely cognitive states like beliefs and the only permissible way of connecting these cognitive states is by means of inference. The second claim Kitcher takes to be part of what constitutes the mainstream conception of the psychology of philosophy is the following:

The changes in belief are sparked by the straightforward presentation of new propositions, ideally stated in precise declarative sentences and accompanied by the explicit presentation of cogent reasons: the newly-believed conclusions are formulated in the work that is read (or by the interlocutor), and, if all goes well, they are backed by lines of reasoning the subject recognizes - the logical relations apprehended by the subject correspond to the logical structure of the text (or conversation). You come to believe that free will is impossible, because I present this proposition to you, and provide for it a valid argument, all of whose premises you already accept. (Kitcher 2013, 19)

Kitcher dismisses the second claim by emphasizing the Quinean point that our acquisition of beliefs depends to a large extent on what other beliefs we already have. And the majority of our beliefs have been acquired not by logical analysis but by perceptual learning or other non-rational means. Hence, we should not treat belief acquisition as a fully rational process. It is not the case that 'you come to believe that free will is impossible, because I present this proposition to you, and provide for it a valid argument, all of whose premises you already accept'. Whether you come to believe that free will is impossible depends on what other (largely not rationally acquired) beliefs you have and how difficult you find it to make the new belief consistent with them. 
And a similar point applies to the revision of our beliefs. We do revise or reevaluate these largely not rationally acquired beliefs. But, Kitcher argues, reading fiction often puts us in a better position to do so than reading a well-polished argument in a philosophy journal.

Kitcher says less about the first assumption. He alludes briefly in a footnote to Damasio 1994 who argues that human thought is through and through emotionally charged (Kitcher 2013, fn. 60), but hesitates to endorse the claim that emotions are a sine qua non of human thoughts (a claim that would deliver his conclusion). As we shall see, there is some recent empirical evidence that human reasoning is, as Kitcher suggests, not a sequence of cognitive states connected by inference.

\section{$V$. Some empirical support}

There is a wealth of recent empirical findings about how we actually reason that seems to flatly contradict the mainstream 'dispassionate quest for truth' picture of human reasoning. Reasoning is sensitive to order effect, to framing effects and even to such banal environmental factors as the dirtiness of one's hands. Maybe the way we should reason is by going through a series of cognitive states connected by inference (more about this possibility below), but it is unlikely that this is what in fact happens when we reason (see also Nanay 2013a, ch. 4).

A couple of famous examples: It has been shown that the wording of the task influences reasoning: depending on whether the same scenario is formulated in terms of the word 'kill' or the word 'save', subjects reason differently (Petrinovich \& O'Neill 1996). The order in which the questions are raised also influences one's reasoning: the subject's conclusion will be different depending on whether task A comes before task B or vice versa (Swain et al. 2008; Petrinovich \& O’Neill 1996).

Further, the way the question or problem is framed also influences our reasoning: if the subject has to decide between a certain amount of money or a $50 \%$ chance of twice that amount of money, the decision depends on whether the subject is about to lose or gain this sum (Tversky \& Kahneman 1981). It is the same problem, but depending on whether it is framed as gain or loss, the outcome of the reasoning process is significantly different.

But reasoning is also influenced by what-completely unrelated-experiences the subject had right before the reasoning process. As Valdesolo \& DeSteno 2006 demonstrated, watching an episode of Saturday Night Live or a (boring) documentary on a small Spanish village has a significant impact on the reasoning afterwards.

Perhaps most surprisingly, such prosaic factors as the cleanliness of one's environment, and even of one's own hands, also influence one's reasoning. Subjects reason differently (for example, concerning moral judgments) depending on whether they are seated in a dirty cubicle with left-over pizza boxes and greasy stains on their desk or they are in a clean environment (Schnall et al. 2008). Hand washing or cleansing also influences our moral reasoning: our responses about what we would be willing to do in specific situations (Zhong \& Liljenquist 2006).

It has also been pointed out that whether we are holding a cup of warm beverage or a glass of cold drink also influences our reasoning about other people (Williams and 
Bargh 2008). I need to emphasize that these are not isolated examples for external effects influencing our reasoning: one additional, quite evocative, example: there is evidence that touching a teddy bear (as opposed to merely seeing one) influences one's reasoning about social behavior (Tai et al. 2011).

Is it possible to accommodate these findings within the framework of the mainstream 'dispassionate quest for the truth' model of reasoning? If this framework were correct, then the findings enumerated above would not be possible: our beliefs and other cognitive states are not altered by the mess on the table in front of us or by the film sketch we have just watched.

One may worry that each of these empirical findings only demonstrate that some external factors influence only specific kinds of reasoning: holding a cup of warm coffee influences our reasoning about the personality-traits of others, but not any other kinds of reasoning processes. Similarly, whether the desk in front of us has pizza stains on it influences our reasoning about moral evaluations, but not other kinds of reasoning. How much can we generalize from these findings then?

The answer is that these findings, put together, demonstrate that reasoning is subject to a wide variety of influences that would not be there if it were a matter of coldly calculating about our beliefs. Whether there are sub-categories of reasoning that are immune to these influences is an open question-there may be some: for examples mathematical or logical reasoning (but there are some recent empirical findings that seem to contradict even this claim: see Morsanyi and Handley 2012). But because of the pervasiveness of these influences, no general account of reasoning can rely on the 'dispassionate quest for truth' framework. And, importantly, we have no reason to hold this as the right way of thinking about philosophical reasoning (see also Swain et al. 2008; Nanay 2013a and 2013b).

A final and more general worry: couldn't we say that while the 'dispassionate quest for truth' model is a normative model of how we should engage with philosophical reasoning, the reality is that we do not always reason the way we should? In this case, all the experiments I mentioned in this section would count as deviations from the norm. A version of this claim is to say that the 'dispassionate quest for truth' model describes rational reasoning, but we are not always and not fully rational beings. And another version of this general claim is that while the 'dispassionate quest for truth' model is the right description of System 2, the automatic and mainly unconscious System 1 often overrides System 2 (Sloman 1996). The general moral of all of these distinctions (normative/descriptive, rational/irrational, System 2/System 1) is that the empirical findings I mentioned above do not challenge the 'dispassionate quest for truth' model, they only explain why it sometimes fails to apply to actual philosophical reasoning.

The short answer is that appealing to normative ideals in this context is extremely problematic. It seems to suggest that philosophizing in a 'dispassionate quest for truth' mode is somehow intrinsically better than philosophizing any other way. But what matters in philosophizing is really the end results. If I arrive at some boring philosophical conclusions, using the 'dispassionate quest for truth' method and you arrive at an exciting new philosophical conclusion with a different method, we should not 
automatically, that is, without even looking at the respective merits of our conclusions, deem your philosophizing to be inferior. As Ian Hacking, Kitcher's ally in many of his philosophical fights, famously said, "the final arbitrator in philosophy is not how we think but what we do" (Hacking 1983, 31).

And at this point Kitcher's Quinean point can be applied. As he emphasizes, our acquisition of beliefs in general, and of beliefs concerning philosophical topics in particular, depends to a large extent on what other beliefs we already have. Whether we come to believe that, say, free will is impossible depends on what other (largely not rationally acquired) beliefs we have and how difficult we find it to make the new belief consistent with them.

Philosophy—even naturalistic philosophy at its extreme-needs to take the 'manifest image' seriously. Besides telling us how the world is, philosophy also needs to tell us how the way the world is relates to the way we take the world to be. This point can be made in Sellarsian terms: while the sciences are about the 'scientific image', the starting point of philosophy is the 'manifest image'. Philosophy then can explore the relation between the 'scientific image' and the 'manifest image' or it can clarify the 'manifest image' itself, independently of what science tells us. But 'manifest image' is part of who we are and it is also part of what philosophy is. In other words, it is not a bias or a bug in philosophical reasoning that it starts out with a set of beliefs that we are dragging along with us and whose rational origins are dubious at best. It is a feature: without this, we would lose what makes philosophy philosophy.

\section{Conclusion: Against the discontinuity in Kitcher's oeuvre}

In conclusion, it is important to see how the picture of our cognitive setup I sketched in the last two sections meshes with Kitcher's claims about pragmatism and about philosophy of science. In both his writings about philosophy of science and his work on pragmatism, Kitcher has been emphasizing the importance of non-rational (or not entirely rational) factors in our life, decision-making and scientific practice. The presupposes something like the picture of our mental life I argued for in the last section. Kitcher himself makes the connection (very tentatively) in chapter 9 of his (Kitcher 2011). If this is true then we should take Kitcher's recent excursions into the philosophy of literature and of music as a serious part of his philosophical views that may elucidate, and that may be elucidated by, his philosophy of science.

\section{REFERENCES}

Damasio, A. 1994. Descartes' Error. New York: Putnam.

Hacking, Ian. 1983. Representing and Intervening. Cambridge: Cambridge University Press.

Kitcher, P. 2007. Joyce's Kaleidoscope: An Invitation to Finnegans Wake. Oxford: Oxford University Press.

—. 2008. Der Ring des Nibelungen. In Handbuch Nietssche Wagner, ed. Stefan Sorgner, pp. 403-8. Roholt.

- 2009. Collideorscape: Finnegans Wake in the large and in the small. Joyce Studies Annual.

—. 2011. The Ethical Project. Cambridge MA: Harvard University Press.

- 2013. Deaths in Venice. New York: Columbia University Press.

—. 2014. The youth without qualities. The Monist (forthcoming in 2014).

—. and R. Schacht 2004. Finding an Ending: Reflections on Wagner's Ring. Oxford: Oxford University Press. 
- and R. Schacht 2006. Authority and Judgment in Mozart's Don Giovanni and Wagner's Ring. In The Don Giovanni Moment, eds. Lydia Goehr and Daniel Herwitz, pp. 161-180. New York: Columbia University Press.

Morsanyi K. and Handley S. J. 2012. Logic feels so good-I like it! Evidence for intuitive detection of logicality in syllogistic reasoning. Journal of Experimental Psychology. Learning, Memory, and Cognition 38: 596616.

Nanay, Bence. 2013a. Between Perception and Action. Oxford: Oxford University Press.

- 2013b. Philosophy versus literature: Against the Discontinuity Thesis. Journal of Aesthetics and Art Criticism 71: in print.

Petrinovich, Lewis and Patricia O'Neill. 1996. Influence of wording and framing effects on moral intuitions. Ethology and Sociobiology 17: 145-171.

Schnall, Simone, Jennifer Benton and Sophie Harvey. 2008. With a Clean Conscience. Cleanliness Reduces the Severity of Moral Judgments. Psychological Science 19: 1219-1222.

Sloman, S. A. 1996. The empirical case for two systems of reasoning. Psychological Bulletin 119: 3-22.

Swain, S., Alexander, J., \& Weinberg, J.M. 2008. The Instability of Philosophical Intuitions. Philosophy and Phenomenological Research 76: 138-155.

Tai, Kenneth, Xue Zheng and Jayanth Narayanan. 2011. Touching a Teddy Bear Mitigates Negative Effects of Social Exclusion to Increase Prosocial Behavior. Social Psychological and Personality Science 2: 618626.

Tversky, Amos and Daniel Kahneman. 1981. The Framing of Decisions and the Psychology of Choice. Science 211: 453-458.

Valdesolo, Piercarlo and David DeSteno. 2006. Manipulations of Emotional Context Shape Moral Judgment. Psychological Science 17: 476-477.

Walton, K. 1990. Mimesis as Make-Believe. Cambridge, MA: Harvard University Press.

Williams, Lawrence E. and John A. Bargh. 2008. Experiencing Physical Warmth Promotes Interpersonal Warmth. Science 322: 606-607.

Williamson, T. 2007. The Philosophy of Philosophy. Oxford: Blackwell.

Zhong, Chen-Bo and Katie Liljenquist. 2006. Washing Away Your Sins: Threatened Morality and Physical Cleansing. Science 313: 1451-1452.

Bence Nanay is Professor of Philosophy and BOF Research professor at the University of Antwerp and Senior Research Associate at Peterhouse, Cambridge University. He is the author of Between Perception and Action (Oxford University Press, 2013) and Aesthetics as Philosophy of Perception (Oxford University Press, forthcoming) and the editor of Perceiving the World (Oxford University Press, 2010).

Address: Centre for Philosophical Psychology, University of Antwerp, D 413, Grote Kauwenberg 18 , 2000 Antwerp, Belgium. E-mail: bence.nanay@ua.ac.be 